\title{
Brief Depression Screening with the PHQ-2 Associated with Prognosis Following Percutaneous Coronary Intervention with Paclitaxel-Eluting Stenting
}

\author{
Susanne S. Pedersen, $P h D^{1,2}$, Johan Denollet, $P h D^{1}$, Peter de Jonge, $P h D^{1,3,4}$, Cihan Simsek, MSc ${ }^{2}$, \\ Patrick W. Serruys, MD, $P h D^{2}$, and Ron T. van Domburg, $P h D^{2}$
}

${ }^{1}$ CoRPS - Center of Research on Psychology in Somatic diseases, Tilburg University, Tilburg, The Netherlands; ${ }^{2}$ Department of Cardiology, Thoraxcenter, Erasmus Medical Center Rotterdam, Rotterdam, The Netherlands; ${ }^{3}$ Department of Internal Medicine, University Medical Center Groningen, University of Groningen, Groningen, The Netherlands; ${ }^{4}$ Department of Psychiatry, University Medical Center Groningen, University of Groningen, Groningen, The Netherlands.

BACKGROUND: Depression is associated with adverse prognosis in cardiac patients, warranting the availability of brief and valid instruments to identify depressed patients in clinical practice.

OBJECTIVES: We examined whether the two-item Patient Health Questionnaire (PHQ-2) was associated with adverse events in percutaneous coronary intervention (PCI) patients treated with paclitaxel-eluting stenting (using the continuous score and various cutoffs), overall and by gender.

DESIGN: Prospective follow-up study.

PARTICIPANTS: Consecutive PCI patients $(\mathrm{n}=796)$ seen at a university medical centre.

MEASUREMENTS: PHQ-2 at baseline. The study endpoint was an adverse event, defined as a combination of death or non-fatal myocardial infarction (MI) at follow-up (mean of 1.4 years).

RESULTS: At follow-up, 47 patients had experienced an adverse event. Using the continuous score of the PHQ-2 and the recommended cutoff $\geq 3$, depressive symptoms were not associated with adverse events ( $p s>0.05$ ). Using a cutoff $\geq 2$, depressive symptoms were significantly associated with adverse events (HR: 1.89; 95\% CI: 1.06-3.35) and remained significant in adjusted analysis (HR: 1.90; 95\% CI: 1.05-3.44). Depressive symptoms were associated with an increased risk of adverse events in men (HR: 2.69; 95\% CI: 1.36-5.32) but not in women (HR: 0.76; 95\% CI: 0.24-2.43); these results remained in adjusted analysis.

CONCLUSIONS: Depression screening with a two-item scale and a cutoff score of $\geq 2$ was independently associated with adverse events at follow-up. The PHQ2 is a brief and valid measure that can easily be used post PCI to identify patients at risk for adverse health outcomes.

Received January 13, 2009

Revised April 22, 2009

Accepted June 09, 2009

Published online July 5, 2009
KEY WORDS: depression; PHQ-2; percutaneous coronary intervention; mortality; women.

J Gen Intern Med 24(9):1037-42

DOI: $10.1007 /$ s1 1606-009-1054-1

(C) Society of General Internal Medicine 2009

\section{INTRODUCTION}

Depression is a common co-morbid disorder of coronary artery disease $(\mathrm{CAD})^{1}$ associated with adverse health outcomes ${ }^{2-7}$. Not only major depressive disorders but also subclinical levels increase the risk of poor prognosis ${ }^{8,9}$. Different depressive symptoms may also exert differential prognostic effects ${ }^{9,10}$. Depression as a prognostic marker has primarily been studied post myocardial infarction (MI), although we previously showed that depressive symptoms are associated with prognosis post percutaneous coronary intervention (PCI) ${ }^{10}$. Knowledge of the potential pathogenic influence of depressive symptoms in PCI patients is important for secondary prevention due to the dramatic increase and projected increase in PCI procedures worldwide ${ }^{11}$.

A recent science advisory from the American Heart Association advocates routine screening for depression in clinical practice using the two-item Patient Health Questionnaire (PHQ) followed by the nine-item PHQ, if screening positive on one or both items of the PHQ- $2^{12}$. Both measures are feasible to use as screening instruments in clinical practice due to their brevity $^{13-15}$. In patients with $\mathrm{CAD}$ and chronic heart failure (CHF), the PHQ-2 has been used in research on clinical depression, quality of life and heart rate variability ${ }^{6,15-21}$, but its prognostic value is as yet to be determined in cardiac patients. By contrast, two studies have investigated the prognostic value of the PHQ-9. Major but not minor depression was associated with a two-fold risk of mortality in $\mathrm{CHF}^{22}$, whereas depression was associated with a range of health outcomes including mortality post $\mathrm{MI}^{23}$. The CHF study failed to find a gender differential prognostic effect for depression ${ }^{22}$.

The PHQ-2 measures the two cardinal symptoms of a clinical diagnosis of depression (i.e., "Little interest or pleasure in doing things"; "Feeling down, depressed, or hopeless") ${ }^{15,24}$. Given the current debate on confounding of depression by CAD severity ${ }^{4}$, a more sound strategy might be to restrict the studying of the role of depression in cardiac prognosis to these cardinal symptoms. Hence, the PHQ-2 may not only be 
superior due to its brevity, but also due to it being less prone to confounding by disease severity compared to the PHQ-9, as the PHQ-9 contains items that are common in cardiac patients (e.g., difficulty sleeping). Even though a cutoff $\geq 3$ on the PHQ2 is recommended $^{24}$, data from the Heart and Soul study indicate that a cutoff $\geq 2$ represents an optimal balance between sensitivity and specificity for identifying major depression in cardiac patients, and is comparable to the PHQ $-9^{25}$. Research is warranted to investigate whether the adoption of different cutoffs has differential prognostic value in cardiac patients ${ }^{15,22}$.

We examined (1) whether the PHQ-2, using a continuous score versus different cutoff scores, is associated with prognosis in PCI patients and (2) whether the PHQ-2 has differential prognostic value in men versus women.

\section{METHODS}

\section{Patients and Design}

Consecutive patients treated with PCI between 15 February 2005 to 14 February 2006 in the Erasmus Medical Center Rotterdam, The Netherlands, comprised the sample for the current study. The paclitaxel-eluting stent was used as the default strategy in our institution during this period. All patients were advised to take clopidogrel for a minimum of 6 months post procedure. Survival status for all patients was obtained 30 days after the index procedure; all surviving patients (referred to as baseline in the remainder of the article) were approached by mail and asked to complete the PHQ-2 ${ }^{15}$. Assessment 30 days post PCI was chosen due to logistic reasons, but also due to concerns that depression assessed too close to the index event may reflect underlying somatic disease rather than depression ${ }^{4,26}$. If the questionnaire was not returned within 3 weeks, a reminder was sent together with a new questionnaire.

The study protocol was approved by the medical ethics committee of the Erasmus Medical Center. All patients provided written informed consent, and the study was carried out in accordance with the Declaration of Helsinki.

\section{MATERIALS}

\section{Demographic and Clinical Variables}

Demographic variables included gender and age. Information on clinical variables, e.g., indication for PCI, multi-vessel disease, previous MI, previous PCI, previous coronary artery bypass graft surgery (CABG), hypertension, hypercholesterolemia, diabetes and cardiac medication (i.e., aspirin, calcium antagonists, betablockers, ACE inhibitors, statins, diuretics, clopidogrel and heparin), were obtained from the patients' medical records. Smoking status was assessed by means of self-report.

\section{Depression}

Depressive symptoms were assessed with the PHQ- $2^{15,24}$. The two symptoms assessed in this questionnaire ("Little interest or pleasure in doing things"; "Feeling down, depressed or hopeless") represent the cardinal symptoms of a clinical diagnosis of depression, according to the diagnostic criteria for clinical depression as listed in the Diagnostic and Statistical Manual of Mental Disorders IV-TR. The items are rated on a 4-point Likert scale from 0 (not at all) to 3 (nearly every day), and the total score range is $0-6$. The PHQ-2 is a valid and internally consistent instrument (Cronbach's alpha $=0.83)^{24}$. A cutoff $\geq 3$ has been proposed to present the most optimal balance between sensitivity and specificity for major depressive disorder and any depressive disorder ${ }^{24}$, although in cardiac patients a cutoff $\geq 2$ seems to present the best balance ${ }^{25}$.

\section{Study Endpoint}

The study endpoint (adverse event) was defined as a combination of death (all-cause) or non-fatal MI. Follow-up was complete for all patients, and the mean follow-up period was 1.4 years. Survival status was obtained from municipal civil registries. Reinfarction was diagnosed by recurrent symptoms and/or new electrocardiographic changes in association with increases in creatine kinase and creatine kinase myoglobin levels of $>3$ times the upper normal limit ${ }^{27}$. A combined endpoint was used due to the small number of events and the fact that combined outcomes are commonly used in cardiovascular outcome studies. As the principal regional cardiac referral center, repeat procedures are normally performed at our institution and recorded prospectively in our database. However, given that several patients are referred from hospitals in the area, and in order to ensure that all MIs and repeat procedures were captured, patients were asked via a postal survey at 1-year if they had experienced an event during the follow-up period. This information was verified against the medical records, and if necessary via general practitioners or referring cardiologists.

\section{Statistical Analysis}

Differences on nominal variables were compared with the chisquare test and on continuous variables with Student's t-test. Unadjusted and adjusted Cox proportional hazard regression analyses were used to examine the impact of depressive symptoms on adverse clinical events. A priori based on the literature, the covariates gender, age, multi-vessel disease, cardiac history (i.e., previous MI, PCI or CABG), hypertension, hypercholesterolemia, diabetes, smoking, ACE inhibitors and statins were selected for inclusion in all multivariable analyses. In secondary analyses, we also included the interaction effect of depressive symptoms by gender to examine whether the PHQ-2 had a differential prognostic effect in men compared to women. We tested the statistical significance of differences in proportions between depressed and non-depressed males and females ${ }^{28}$ and $\chi^{2}$ differences, using Cohen's effect size index $w^{29}$. According to the thresholds for the effect size statistic $w$ for differences between proportions, an effect size of 0.10 is considered small, 0.30 medium and 0.50 large. All tests were two-tailed ( $p$-value $<$ 0.05); for Cox proportional hazard regression analyses, hazard ratios (HR) and their corresponding 95\% confidence intervals (CI) are reported. All data were analyzed using SPSS 17.0 for Windows (SPSS Inc., Chicago, IL).

\section{RESULTS}

\section{Non-responders Versus Responders on Baseline Characteristics}

Of 1,238 eligible patients treated with PCI in the study period, 66 died within 30 days. The remaining 1,172 patients were 
asked to participate in the study, of which $870(74.2 \%)$ agreed. Responders $(n=870)$ were more likely to be older (mean $62.7 \pm$ 11.5 versus $60.2 \pm 13.4 ; p=0.006$ ), to have hypercholesterolemia $(81.0 \%$ versus $71.9 \% ; p=0.001)$ and to be prescribed aspirin $(92.6 \%$ versus $87.1 \% ; p=0.005)$ compared to nonresponders $(n=302)$. No other statistically significant differences were found between responders and non-responders on baseline characteristics. Analyses are based on 796 patients who had completed the PHQ-2.

\section{Baseline Characteristics of the Sample}

The mean depression score on the PHQ-2 was $1.01 \pm 1.42$ at baseline. The prevalence of depressive symptoms was $45.9 \%$ (365/796) for cutoff $\geq 1,30.2 \%(240 / 796)$ for cutoff $\geq 2$ and $11.9 \%$ (95/796) for cutoff $\geq 3$.

Baseline characteristics stratified by depressive symptoms using the cutoff $\geq 2^{25}$ and $\geq 3^{24}$ on the $\mathrm{PHQ}-2$ are presented in Table 1 . Using the cutoff $\geq 2$, depressed patients were more likely to have had a previous MI, previous PCI, hypercholesterolemia, diabetes, to be smoking, and to be prescribed ACE inhibitors and statins. No other statistically significant differences were found between depressed and non-depressed patients on baseline characteristics.

Using the cutoff $\geq 3$, depressed patients were more likely to have had a previous MI and to be prescribed ACE inhibitors compared to non-depressed patients. No other statistically significant differences were found between depressed and nondepressed patients on baseline characteristics.
HR: 1.89 [95\% Cl: 1.06-3.35]

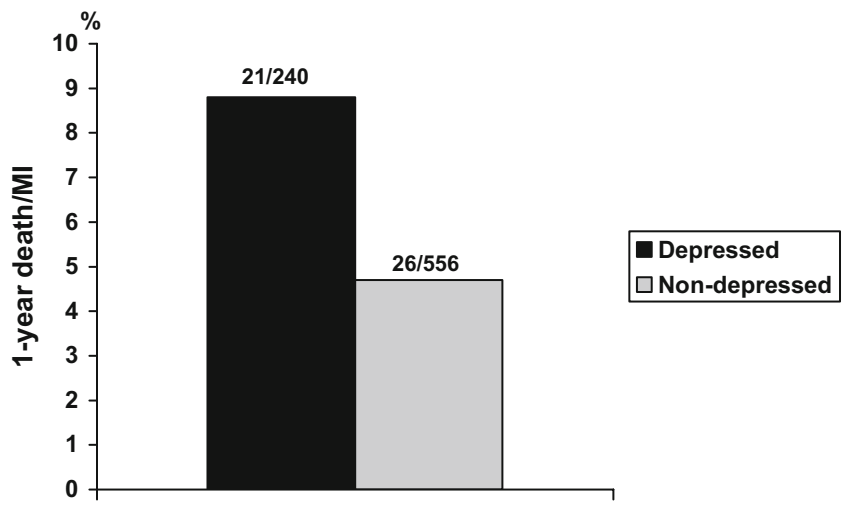

* The number of depressed versus non-depressed patients who had an adverse event during the follow-up period is listed on top of bars

Figure 1. Incidence of adverse events stratified by depressive symptomatology (PHQ-2 cutoff $\geq 2$ )*.

\section{Depressive Symptoms and Adverse Events}

There were 47 adverse events (deaths=35; MIs=12). In unadjusted analysis, the continuous PHQ-2 depression score was not significantly related to adverse events at follow-up (HR: 1.15; 95\% CI: 0.97-1.36; $p=0.12$ ). The cutoff $\geq 3$ on the PHQ-2 was also not significantly associated with adverse events (HR: 1.27; 95\% CI: 0.57-2.83; $p=0.57$ ). However, with a cutoff $\geq 2$, the incidence of adverse events was significantly higher in

Table 1. Baseline Characteristics for the Total Sample and Stratified by Depressive Symptoms (PHQ-2 Cutoff $\geq 2$ and $\geq 3$ )*

\begin{tabular}{|c|c|c|c|c|c|c|c|}
\hline & \multirow{2}{*}{$\begin{array}{l}\text { Total } \\
\mathrm{n}=796\end{array}$} & \multicolumn{3}{|c|}{ PHQ-2 cutoff $\geq 2$} & \multicolumn{3}{|c|}{$P H Q-2$ cutoff $\geq 3$} \\
\hline & & $\begin{array}{l}\text { Depressed } \\
(n=240)\end{array}$ & $\begin{array}{l}\text { Non-depressed } \\
(n=556)\end{array}$ & $p$ & $\begin{array}{l}\text { Depressed } \\
(n=95)\end{array}$ & $\begin{array}{l}\text { Non-depressed } \\
(n=701)\end{array}$ & $P$ \\
\hline \multicolumn{8}{|l|}{ Demographics } \\
\hline Male gender & $574(72.1)$ & $164(68.3)$ & $410(73.7)$ & 0.14 & $64(67.4)$ & $510(72.8)$ & 0.33 \\
\hline Age, mean $\pm \mathrm{SD}$ & $62.5 \pm 11.5$ & $62.2 \pm 11.9$ & $62.7 \pm 11.4$ & 0.59 & $63.8 \pm 12.0$ & $62.4 \pm 11.4$ & 0.25 \\
\hline \multicolumn{8}{|l|}{ Clinical } \\
\hline Indication for PCI (MI) & $264(33.2)$ & 84 (35.0) & $180(32.4)$ & 0.52 & $34(35.8)$ & $230(32.8)$ & 0.64 \\
\hline Multi-vessel disease & $379(47.6)$ & $109(45.4)$ & $270(48.6)$ & 0.46 & 47 (49.5) & $332(47.4)$ & 0.78 \\
\hline Previous MI & $216(27.1)$ & 79 (32.9) & $137(24.6)$ & 0.02 & $38(40.0)$ & $178(25.4)$ & 0.004 \\
\hline Previous PCI & $223(28.0)$ & $82(34.2)$ & $141(25.4)$ & 0.01 & $29(30.5)$ & $194(27.7)$ & 0.65 \\
\hline Previous CABG & $71(8.9)$ & 27 (11.3) & 44 (7.9) & 0.17 & $13(13.7)$ & $58(8.3)$ & 0.12 \\
\hline Hypertension $^{\dagger}$ & $343(43.1)$ & $105(43.8)$ & $238(42.8)$ & 0.87 & $40(42.1)$ & $303(43.2)$ & 0.92 \\
\hline Hypercholesterolemia ${ }^{\ddagger}$ & $648(81.4)$ & $210(87.5)$ & $438(78.8)$ & 0.005 & $82(86.3)$ & $566(80.7)$ & 0.24 \\
\hline Diabetes $^{\S}$ & $137(17.2)$ & $53(22.1)$ & $84(15.1)$ & 0.02 & $22(23.2)$ & $115(16.4)$ & 0.14 \\
\hline Smoking $\square$ & $202(25.4)$ & $76(31.7)$ & $126(22.7)$ & 0.01 & $28(29.5)$ & $174(24.8)$ & 0.39 \\
\hline \multicolumn{8}{|l|}{ Medication } \\
\hline Aspirin & $742(93.2)$ & 229 (95.4) & $513(92.3)$ & 0.14 & 89 (93.7) & $653(93.2)$ & 1.00 \\
\hline Calcium antagonists & $14(1.8)$ & $3(3.1)$ & $11(2.0)$ & 0.67 & $1(1.1)$ & 13 (1.9) & 0.89 \\
\hline Beta-blockers & $499(62.7)$ & $155(64.6)$ & $344(61.9)$ & 0.52 & $57(60.0)$ & $442(63.1)$ & 0.64 \\
\hline ACE inhibitors & $295(37.1)$ & $108(45.0)$ & $187(33.6)$ & 0.003 & $45(47.4)$ & $250(35.7)$ & 0.04 \\
\hline Statins & $583(73.2)$ & $189(78.8)$ & 394 (70.9) & 0.03 & $73(76.8)$ & $510(72.8)$ & 0.47 \\
\hline Diuretics & 76 (9.5) & $25(10.4)$ & $51(9.2)$ & 0.68 & $11(11.6)$ & 65 (9.3) & 0.60 \\
\hline Clopidogrel & 796 (100) & $240(100)$ & 556 (100) & 1.00 & 95 (100) & 701 (100) & 1.00 \\
\hline Heparin & 127 (16.0) & 43 (17.9) & $84(15.1)$ & 0.38 & $12(12.6)$ & 115 (16.4) & 0.43 \\
\hline
\end{tabular}

*Results are presented as numbers (\%), unless otherwise indicated

$M I=$ myocardial infarction; $P C I=$ percutaneous coronary intervention; $C A B G=$ coronary artery bypass graft surgery

${ }^{\dagger} 140 / 90 \mathrm{mmHg}$ or being treated for hypertension

* $\geq 240 \mathrm{mg} / \mathrm{dl}$ or being treated for hypercholesterolemia

${ }^{\S}$ Being treated for diabetes

Based on the patient's self-report 
Table 2. Hazard Ratios, $95 \% \mathrm{Cl}$ and $\mathrm{P}$-values from Adjusted Models Regressing Depressive Symptoms (Cutoff $\geq 2$ ) and Other Factors on Adverse Events*

\begin{tabular}{llll}
\hline \hline & HR & $(95 \% \mathrm{Cl})$ & $\boldsymbol{P}$ \\
\hline Depressive symptoms & 1.90 & {$[1.05-3.44]$} & 0.03 \\
Male gender & 1.12 & {$[0.59-2.15]$} & 0.73 \\
Age & 1.05 & {$[1.02-1.08]$} & 0.002 \\
Multi-vessel disease $^{\dagger}$ & 1.37 & {$[0.75-2.48]$} & 0.31 \\
Cardiac history $^{\dagger}$ & 0.79 & {$[0.42-1.50]$} & 0.47 \\
Hypertension $^{\ddagger}$ & 0.79 & {$[0.42-1.52]$} & 0.48 \\
Hypercholesterolemia $^{\S}$ & 0.68 & {$[0.28-1.61]$} & 0.38 \\
Diabetes $^{\square}$ & 1.90 & {$[0.94-3.86]$} & 0.08 \\
Smoking $^{\text {qI }}$ & 2.44 & {$[1.28-4.65]$} & 0.007 \\
ACE inhibitors $^{\text {Statins }}$ & 0.99 & {$[0.50-1.97]$} & 0.98 \\
\end{tabular}

*Adjusted Cox proportional hazard regression analysis

${ }^{\dagger}$ Previous MI, PCI or CABG

${ }^{\ddagger} 140 / 90 \mathrm{mmHg}$ or being treated for hypertension

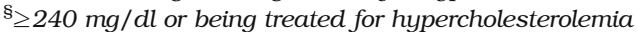

$\square$ Being treated for diabetes

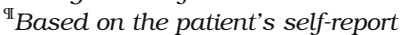

depressed versus non-depressed (8.8\% versus $4.7 \%$; HR: 1.89 ; 95\% CI: 1.06-3.35; $p=0.03$ ) (Fig. 1).

Given that neither the continuous PHQ-2 depression score nor the cutoff $\geq 3$ was significantly associated with adverse events in unadjusted analysis, adjusted analysis was only performed for the cutoff $\geq 2$. Depressive symptoms (HR: 1.90 ; 95\% CI: $1.05-$ $3.44 ; p=0.03$ ) remained an independent correlate of adverse events at follow-up in adjusted analysis (Table 2).

To further disentangle the relationship between depressive symptoms and adverse events, we examined the separate effects of item 1 (i.e., "Little interest or pleasure in doing things") and item 2 (i.e., "Feeling down, depressed, or hopeless") on adverse events. Labeling a response from 1-3 as a positive response, item 2 (HR: 2.05; 95\% CI: 1.16-3.64; $p=0.01$ ) was significantly associated with adverse events, and there was a trend for item 1 (HR: 1.74 ; 95\% CI: 0.98-3.09; $p=0.06$ ), suggesting that the relationship between depressive symptoms and prognosis was driven by both items, but to a greater extent by anhedonia.

\section{Differential Prognostic Effect of the PHQ-2 on Gender}

To examine whether the cutoff $\geq 2$ on the PHQ-2 had a differential prognostic effect in men and women, we ran secondary analyses including the interaction effect of depressive symptoms by gender together with the main effects. The number of adverse events at follow-up in men was 33 and 14 in women. In unadjusted analysis, there was a clear trend for the interaction effect (HR: 3.52; 95\% CI: 0.92-13.52; $p=0.06$ ). Performing separate analyses in male and female patients, the incidence of adverse events was higher in depressed versus non-depressed men (10.4\% versus 3.9\%; HR: 2.69; 95\% CI: $1.36-$ $5.32 ; p=0.005)$, but not in depressed versus non-depressed women $(5.3 \%$ versus 6.8 ; HR: $0.76 ; 95 \%$ CI: $0.24-2.43$; $p=0.64)$. The difference in proportions between depressed versus non-depressed men who experienced an event was 6.5 (95\% CI: 1.1-11.5), with Cohen's effect size $w=0.13$ indicating a small effect. By comparison, the difference in proportions was $1.6(95 \%$ CI -4.8-8.1) in depressed versus non-depressed women. An effect size was not calculated for women, as it makes no sense to estimate the differences when these are based on random variation.

In adjusted analysis, depressive symptoms (HR: 2.30; 95\% CI: $1.13-4.69 ; p=0.02$ ) remained an independent correlate of adverse events at follow-up in men, whereas there was no effect in women (Table 3).

\section{DISCUSSION}

Depression is an important risk marker for adverse prognosis in cardiac patients and has also been associated with secondary outcomes, including impaired quality of life, poor adherence and rehospitalizations ${ }^{2-7}$. Given time pressure in clinical cardiology practice, the availability of brief and valid screening instruments, such as the PHQ-2 and the PHQ-9, to identify patients at risk for depression is important as an alternative to time-consuming, clinical diagnostic interviews ${ }^{13}$. To our knowledge, only two studies have examined the prognostic

Table 3. Hazard Ratios, $95 \% \mathrm{Cl}$ and P-values from Adjusted Models Regressing Depressive Symptoms (Cutoff $\geq 2$ ) and Other Factors on Adverse Events, Stratified by Gender*

\begin{tabular}{|c|c|c|c|c|c|c|}
\hline & \multicolumn{3}{|c|}{ Men $(n=574)$} & \multicolumn{3}{|c|}{ Women $(n=222)$} \\
\hline & HR & $(95 \% \mathrm{Cl})$ & $\mathbf{P}$ & HR & $(95 \% \mathrm{Cl})$ & $\mathbf{P}$ \\
\hline Depressive symptoms & 2.30 & [1.13-4.69] & 0.02 & 1.08 & [0.30-3.99] & 0.90 \\
\hline Age & 1.06 & [1.02-1.09] & 0.001 & 1.02 & [0.97-1.07] & 0.49 \\
\hline Multi-vessel disease & 1.40 & {$[0.68-2.91]$} & 0.36 & 1.01 & [0.34-3.03] & 0.98 \\
\hline Cardiac history $^{\dagger}$ & 0.67 & {$[0.31-1.45]$} & 0.31 & 1.13 & {$[0.35-3.66]$} & 0.84 \\
\hline Hypertension & 0.68 & {$[0.31-1.47]$} & 0.32 & 1.16 & {$[0.35-3.86]$} & 0.81 \\
\hline Hypercholesterolemia ${ }^{\S}$ & 0.88 & {$[0.29-2.68]$} & 0.82 & 0.55 & {$[0.12-2.54]$} & 0.44 \\
\hline Diabetes & 2.05 & {$[0.88-4.78]$} & 0.10 & 1.24 & {$[0.32-4.83]$} & 0.76 \\
\hline Smoking $^{\mathrm{qI}}$ & 3.15 & {$[1.48-6.70]$} & 0.003 & 1.28 & {$[0.32-5.04]$} & 0.73 \\
\hline ACE inhibitors & 1.06 & {$[0.48-2.34]$} & 0.88 & 0.91 & {$[0.21-3.90]$} & 0.90 \\
\hline Statins & 0.71 & [0.26-1.89] & 0.49 & 0.40 & [0.09-1.78] & 0.23 \\
\hline
\end{tabular}

*Adjusted Cox proportional hazard regression analysis

${ }^{\dagger}$ Previous MI, PCI or CABG

${ }^{\ddagger} 140 / 90 \mathrm{mmHg}$ or being treated for hypertension

$\S_{\geq 2} 40 \mathrm{mg} /$ dl or being treated for hypercholesterolemia

$\square$ Being treated for diabetes

${ }^{\mathrm{II}}$ Based on the patient's self-report 
value of the $\mathrm{PHQ}$ in cardiac patients, with both studies using the $\mathrm{PHQ}-9^{22,23}$

We examined the prognostic value of different cutoffs on the PHQ-2 in PCI patients. A cutoff $\geq 3$ has been recommended to screen for depressive disorder in primary care ${ }^{14}$. However, other cutoff scores may be considered ${ }^{24}$, in particular given that the PHQ-2 to date has been used less in research than the PHQ $-9^{16}$. Data from the Heart and Soul study showed that a PHQ-2 cutoff $\geq 2$ exhibited an optimal balance between sensitivity and specificity for identifying major depression in cardiac patients, and was comparable to the PHQ- ${ }^{25}$. The current study confirms that relatively low levels of depressive symptoms may identify high-risk patients ${ }^{10}$, as a cutoff $\geq 2$ on the PHQ-2 was associated with poor prognosis. Hence, a cutoff $\geq 2$ on the PHQ-2 seems to present the best balance between sensitivity and specificity as a screening instrument for major depression in cardiac patients ${ }^{25}$, but also to have the best prognostic value.

We also found that the incidence of adverse events was higher in depressed than non-depressed men, but not in depressed versus non-depressed women. Given the wide confidence intervals related to the interaction effect and the fewer events in women, this finding should be interpreted with some caution. In the general cardiovascular literature, depression has been shown to exert a similar prognostic effect in men and women ${ }^{22,30,31}$, although some earlier studies reported a more malignant effect in women ${ }^{32}$. Differences in the prevalence of depression could not explain the differential prognostic influence found in the current study, as men and women did not differ in depressive symptoms. Women are generally known to report more symptoms of depression than men, although this has been supported in some ${ }^{18,31,33,34}$, but not all studies of cardiac patients ${ }^{22}$.

The results of the current study have implications for research and clinical practice, and extend those of previous research, demonstrating that the $\mathrm{PHQ}-2$ may help identify high-risk patients despite state-of-the-art treatment in interventional cardiology. The $\mathrm{PHQ}-2$ is a valid and reliable screening instrument ${ }^{15,24}$ that can easily be used for research purposes and in clinical practice due to its brevity. The PHQ-2 is also sensitive to tapping treatment-related changes ${ }^{24}$, making it suitable to use as an outcome measure in clinical and intervention trials. Nevertheless, there is as yet no evidence to show that intervening against depression has any benefit on survival $^{35}$.

The current study has some limitations. First, the number of clinical events was 47 , potentially leading to overfitting of the adjusted models due the number of covariates included. Hence, in secondary analyses the power may have been too low to find a significant effect for depression in women, if present. Second, a selection bias may have occurred, as patients who died within the first 30 days post PCI did not have the opportunity to participate. However, these patients are more likely to have died due to medical complications than their psychological profile. In addition, assessment of depressive symptoms at the time of the index PCI may not be the most optimal, as symptoms may reflect the underlying somatic disease rather than depression ${ }^{4,24}$. Third, we had no information on the cause of death. Fourth, we had no information on depression status prior to the index PCI, the use of psychotropic medication, participation in cardiac rehabilitation and education, which could have influenced the results. Fifth, although all patients were advised to take clopidogrel for at least 6 months, we do not know if patients took their medication as prescribed, and we could not control statistically for potential variability in the duration of clopidogrel therapy. Sixth, hypercholesterolemia was associated with a reduced risk of poor prognosis both in the total sample and in women, which seems counterintuitive. However, hypercholesterolemia was defined as $\geq 240 \mathrm{mg} / \mathrm{dl}$ or being treated for hypercholesterolemia. Secondary prevention guidelines advocate that all patients with $\mathrm{CAD}$ be prescribed statin therapy irrespective of whether they have hypercholesterolemia $^{36}$. Hence, there is likely a considerable overlap between the variables statin use and hypercholesterolemia. Finally, it is possible that the differential prognostic effects of the cutoff scores $\geq 2$ versus $\geq 3$ on the $\mathrm{PHQ}-2$ may be attributed to anti-depressant therapy being more prevalent in patients with the higher cutoff. However, this explanation seems unlikely, given evidence from large-scale trials in cardiac patients ${ }^{37,38}$, showing that antidepressant therapy may reduce depression but not enhance survival. Similarly, it is possible that differences in cardiac medication between the two cutoffs would be responsible for their differential prognostic effects. Again, we deem this unlikely, as there is not a consistent pattern for the two cutoffs in terms of differences in medication use or evidence in the literature to suggest that depressive symptoms are associated with cardiac medication, such as beta-blocker ${ }^{39}$ or statin therapy ${ }^{40}$.

Despite these potential limitations, this study makes an important contribution to the literature on depression as a risk factor for adverse prognosis in cardiac patients. To our knowledge, it is the first study to examine the prognostic value of the PHQ-2 in cardiac patients and also the potential differential effects of the two depressive symptoms contained within the $\mathrm{PHQ}-2$.

In conclusion, in PCI patients treated with the paclitaxeleluting stent the two-item PHQ (cutoff $\geq 2$ ) was associated with poor prognosis, with depressed patients having a two-fold independent risk of adverse events. The PHQ-2 is a brief and valid measure that can easily be used in clinical practice to identify patients at risk for depression and adverse health outcomes. Although our results suggest that depressive symptoms may exert a more deleterious effect in men than in women, this should be confirmed in future studies.

Acknowledgements: There was no external or internal funding for this project.

\section{Conflict of Interest: None disclosed.}

Corresponding Author: Susanne S. Pedersen, PhD; CoRPS, Department of Medical Psychology, Tilburg University, Room P506, Warandelaan 2, P.O. Box 901535000 LE, Tilburg, The Netherlands (e-mail: s.s. pedersen@uvt.nl, URL: http://www.tilburguniversity.nl/corps/).

\section{REFERENCES}

1. Thombs BD, Bass EB, Ford DE, et al. Prevalence of depression in survivors of acute myocardial infarction. J Gen Intern Med. 2006;21:30-8.

2. Jiang W, Alexander J, Christopher E, et al. Relationship of depression to increased risk of mortality and rehospitalization in patients with congestive heart failure. Arch Intern Med. 2001;161:1849-56.

3. Van Melle JP, de Jonge P, Spijkerman TA, et al. Prognostic association of depression following myocardial infarction with mortality and cardiovascular events: a meta-analysis. Psychosom Med. 2004;66:814-22. 
4. Nicholson A, Kuper H, Hemingway $\mathbf{H}$. Depression as an aetiologic and prognostic factor in coronary heart disease: a meta-analysis of 6,362 events among 146,538 participants in 54 observational studies. Eur Heart J. 2006;27:2763-74.

5. Rumsfeld JS, Havranek E, Masoudi FA, et al. Cardiovascular Outcomes Research Consortium. Depressive symptoms are the strongest predictors of short-term declines in health status in patients with heart failure. J Am Coll Cardiol. 2003;42:1811-17.

6. Müller-Tasch T, Peters-Klimm F, Schellberg D, et al. Depression is a major determinant of quality of life in patients with chronic systolic heart failure in general practice. J Cardiac Fail. 2007;13:818-24.

7. Dimatteo MR, Lepper HS, Croghan TW. Depression is a risk factor for noncompliance with medical treatment: meta-analysis of the effects of anxiety and depression in patient adherence. Arch Intern Med. 2000;160:2101-7.

8. Lespérance F, Frasure-Smith N, Juneau M, Théroux P. Depression and 1-year prognosis in unstable angina. Arch Intern Med. 2000; 160:135460 .

9. de Jonge P, Ormel J, van den Brink RH, et al. Symptom dimensions of depression following myocardial infarction and their relationship with somatic health status and cardiovascular prognosis. Am J Psychiatry. 2006; 163:138-44.

10. Pedersen SS, Denollet J, Daemen J, et al. Fatigue, depressive symptoms, and hopelessness as predictors of clinical events following percutaneous coronary intervention with paclitaxel-eluting stents. J Psychosom Res. 2007;62:455-61.

11. Cook S, Walker A, Hügli O, Togni M, Meier B. Percutaneous coronary interventions in Europe: prevalence, numerical estimates, and projections based on data up to 2004. Clin Res Cardiol. 2007;96:375-82.

12. Lichtman JH, Bigger JT, Blumenthal JA, et al. Depression and coronary heart disease. Recommendations for screening, referral and treatment. Circulation. 2008;118:1768-75.

13. Whooley MA, Avins AL, Miranda J, Browner WS. Case-finding instruments for depression. Two questions are as good as many. J Gen Intern Med. 1997; 12:439-45.

14. Kroenke K, Spitzer RL, Williams JB. The PHQ-9: validity of a brief depression severity measure. J Gen Intern Med. 2001;16:606-13.

15. Kroenke K, Spitzer RL, Williams JB. The Patient Health Questionnaire-2: validity of a two-item depression screener. Med Care. 2003;41:1284-92.

16. Gilbody S, Richards D, Brealey S, Hewitt C. Screening for depression in medical settings with the patient health questionnaire (PHQ): A diagnostic meta-analysis. J Gen Intern Med. 2007;22:1596-1602.

17. McManus D, Pipkin SS, Whooley MA. Screening for depression in patients with coronary heart disease (Data from the Heart and Soul Study). Am J Cardiol. 2005;96:1076-81.

18. Mallik S, Spertus JA, Reid KJ, et al. For the PREMIER Registry Investigators. Depressive symptoms after acute myocardial infarction. Arch Intern Med. 2006;166:876-83.

19. Ruo B, Rumsfeld JS, Hlatky MA, Liu H, Browner WS, Whooley MA. Depressive symptoms and health-related quality of life: The Heart and Soul Study. JAMA. 2003;290:215-21.

20. de Jonge P, Mangano D, Whooley MA. Differential association of cognitive and somatic depressive symptoms with heart rate variability in patients with stable coronary heart disease: Findings from the Heart and Soul Study. Psychosom Med. 2007;69:735-9.

21. Holzapfel N, Müller-Tasch T, Wild B, et al. Depression profile in patients with and without chronic heart failure. J Affect Disord. 2008; 105:53-62.
22. Faller H, Störk S, Schowalter M, Steinbüchel T, Wollner V, Ertl G, Angermann CE. Depression and survival in chronic heart failure: does gender play a role? Eur J Heart Fail. 2007;9:1018-23.

23. Parashar S, Rumsfeld JS, Spertus JA, et al. Time course of depression and outcome of myocardial infarction. Arch Intern Med. 2006; 166:2035-43.

24. Löwe B, Kroenke K, Gräfe K. Detecting and monitoring depression with a two-item questionnaire (PHQ-2). J Psychosom Res. 2005;58:163-71.

25. Thombs BD, Ziegelstein RC, Whooley MA. Optimizing detection of major depression among patients with coronary artery disease using the Patient Health Questionnaire: Data from the Heart and Soul Study. J Gen Intern Med. 2008;12:2014-7.

26. Poston WS, Haddock CK, Conard MW, Jones P, Spertus J. Assessing depression in the cardiac patient. When is the appropriate time to assess depression in the patient undergoing coronary revascularization? Behav Modif. 2003;27:26-36.

27. Daemen J, Tanimoto S, Garcia-Garcia HM, et al. Comparison of threeyear clinical outcome of sirolimus- and paclitaxel-eluting stents versus bare metal stents in patients with ST-segment elevation myocardial infarction (from the RESEARCH and T-SEARCH Registries). Am J Cardiol. 2007;99:1027-32

28. Newcombe RG, Altman DG. Proportions and their differences. In: Altman DG, Machin D, Bryant TN, Gardner MJ, eds. Statistics with confidence. 2nd ed. Bristol: British Medical Journal;2005:45-56.

29. Cohen J. Chi-Square Tests for Goodness of Fit and Contingency Tables. Statistical Power Analysis for the Behavioural Sciences. 2nd ed. Hillsdale Lawrence Erlbaum Associates; 1988:215-71.

30. Barefoot JC, Helms MJ, Mark DB, et al. Depression and long-term mortality risk in patients with coronary artery disease. Am J Cardiol. 1996;78:613-7.

31. Frasure-Smith N, Lespérance F, Juneau M, Talajic M, Bourassa MG. Gender, depression, and 1-year prognosis after myocardial infarction. Psychosom Med. 1999;61:26-37.

32. Greenland P, Reicher-Reiss H, Goldbourt U, Behar S. In-hospital and 1-year mortality in 1,524 women after myocardial infarction. Comparison with 4,315 men. Circulation. 1991:83:484-91.

33. Dunn SL, Corser W, Stommel M, Holmes-Rovner M. Hopelessness and depression in the early recovery period after hospitalization for acute coronary syndrome. J Cardiopulm Rehabil. 2006;26:152-9.

34. Vaccarino V, Lin ZQ, Kasl SV, Mattera JA, Roumanis SA, Abramson JL, Krumholz HM. Gender differences in recovery after coronary artery bypass surgery. J Am Coll Cardiol. 2003;41:307-14

35. Thombs BD, de Jonge $\mathbf{P}$, Coyne JC, et al. Depression screening and patient outcomes in cardiovascular care: a systematic review. JAMA. 2008:300:2161-71

36. Graham I, Atar D, Borch-Johnsen K, et al. European guidelines on cardiovascular disease prevention in clinical practice: executive summary. Eur J Cardiovasc Prev Rehabil. 2007; 14:S1-78.

37. Glassmann AH, O'Connor CM, Califf RM, Swedberg K, et al. Sertraline treatment of major depression in patients with acute MI or unstable angina. JAMA. 2002;288:701-9.

38. van Melle JP, de Jonge $P$, Honig A, et al. Effects of antidepressant treatment following myocardial infarction. Br J Psychiatry. 2007;190:460-6.

39. van Melle JP, Verbeek DE, van den Berg MP, et al. Beta-blockers and depression after myocardial infarction: a multicenter prospective study. $\mathrm{J}$ Am Coll Cardiol. 2006;48:2209-14.

40. Agostini JV, Tinetti ME, Han L. Effects of statin use on muscle strength, cognition, and depressive symptoms in older adults. J Am Geriatr Soc. 2007;55:420-5. 